\title{
EFFECT OF SURFACE TREATMENT OF ORTHODONTIC MINI-SCREW IMPLANTS ON THEIR STABILITY; IN VIVO STUDY
}

\author{
Shaza Mohammad Hammad* and Ahmad Mohammad Hafez**
}

\begin{abstract}
Purpose: To evaluate the effect of anodization surface treatment on the stability of minimplants ( MIs ) during en-masse retraction.

Materials and Methods: The sample of this split mouth; clinical trial, consisted of 27 patients with an allocation ratio of 1:1. Forty five MIs (1.8 mm diameter and $8 \mathrm{~mm}$ length) were divided into: 27 MIs with surface treatment by anodization technique while the other 27 were with smooth surface (group B). Finishing, leveling and alignment, the surface treated MIs and the smooth ones were randomly inserted between the roots of maxillary 2nd bicuspid and 1st molar at the mucogingival junction on both sides of each patient. After two weeks healing period, bilateral extraction of maxillary $1^{\text {st }}$ bicuspids were done. Closed coil spring was extended from the MI head to along hock secured onto the main arch wire between the maxillary lateral incisor and canine on both sides, delivering $200 \mathrm{~g}$ force per side to en-masse retract the upper anterior teeth. The average observation period lasted 9-12 months.
\end{abstract}

Results: In total, 40 of 54 minimplants were able to achieve the treatment goals. In group A, $22(81.5 \%)$ mini-screw implants presented long-term stability, while in group B, only $18(66 \%)$ minimplants were stable throughout the treatment. This difference was statistically significant $(\mathrm{P}$ $=.0311$ ). The total success rate for all inserted miniscrew implants was $74 \%$.

Conclusion: Anodized surface treated orthodontic mini-screw implants are more stable than smooth surface one during en-mass retraction.

\section{INTRODUCTION}

Anchorage is a basic concept for orthodontic treatment. ${ }^{1}$ Poor anchorage control may increase treatment time and lead to an unfavorable out- comes. ${ }^{2}$ Orthodontists were unable to have infinite or absolute anchorage (zero anchorage loss) to prevent undesirable tooth movement till the emerge of orthodontic mini implants (MIs). ${ }^{1}$

* Professor, Department of Orthodontics, Faculty of Dentistry, Mansoura University, Mansoura, Egypt.

** Lecturer, Department of Orthodontics, Faculty of Dentistry, Mansoura University, Mansoura, Egypt. 
MIs had widened the horizon of orthodontic treatments. They allowed orthodontists to perform various treatment modalities that were considered extremely difficult, if not impossible such as, enmasse retraction of anterior teeth and distalization of the whole dentition without loss of anchorage. ${ }^{3}$

Stability of MIs is a key for successful orthodontic treatment specially when inserted in the inter-radicular areas between roots of the teeth and in long term loading cases to guard against displacement. This displacement might hit vital organs as nerves or contact neighboring roots and might indicate mid- treatment redirection for the MIs position., ${ }^{4,5}$

Treatment of the MIs surface by anodization was proven by Kim et $\mathrm{al}^{6}$ and Cho et $\mathrm{al}^{7}$ to be an efficient surface treatment technique. They revealed greater bone to implants contact and increased removal torque value of MIs treated by such technique compared compared to other surface treatment techniques.

Modification of MIs surface seems to be a promising factor for improving their stability and decreasing their failure rate. However, there was insufficient data or consensus about the comparison of the stability of surface treated and smooth surface MIs; heavily loaded for long duration Therefore, this study aimed to evaluate the effect of surface treatment on the stability of MIs during en-masse retraction. The null hypothesis was that there is no difference between the stability of surface treated and non-treated minimplants.

\section{MATERIALS AND METHODS}

This in-vivo study was a split mouth, randomized controlled clinical trial with an allocation ratio of 1:1. A sample of 27 Egyptian female patients seeking orthodontic treatment at the clinic of orthodontic department, Faculty of Dentistry, Mansoura University, were enrolled for this study. to:This study was done according to the Orthodontic Department research plan which was approved by the Faculty of Dentistry, Mansoura University's Council.

The patients were randomly selected according to the following criteria: age ranged from 1820 years old, orthodontic treatment plan entailed absolute anchorage to en-mass retraction of the maxillary anterior teeth in Angle's class II division 1 malocclusions, having no or mild crowding, no systemic disease, no history of using drugs altering bone metabolism and good oral hygiene. The exclusion criteria were: any radiographic evidence of bone loss or pathologic diseases, evidence of periodontal or gingival problems at the beginning of orthodontic treatment, harmful oral habits like (thumb sucking and tongue thrusting), any history of trauma or systemic diseases or previous orthodontic treatment.

Before the beginning of treatment, orthodontic records were taken. Forty five smooth surface MIs*, $8 \mathrm{~mm}$ length and $1.8 \mathrm{~mm}$ diameter made from biocompatible titanium alloy (Ti $6 \mathrm{Al} 4 \mathrm{~V}$ ) were used in this study (Figure 1). They were divided into two groups: the first group (group A) had 27 MIs that were surface treated as described later, the $2^{\text {nd }}$ group (group B) had 27 smooth surface MIs, left as they were supplied from the manufacturer acting as a control group.

For preparing the minimplants for surface treatment, an anodization process was performed. It is an electrochemical reaction where the MI was included in an electrical cell containing a mixture of 1 Mole $\mathrm{H}_{2} \mathrm{SO}_{4}$ and phosphoric acid $\left(\mathrm{H}_{3} \mathrm{PO}_{4}\right)^{*}$ as electrolytes. Each MI was connected to anode, while the cathode was a platinum sheet. The distance between them was $4 \mathrm{~cm}$ without agitation at 


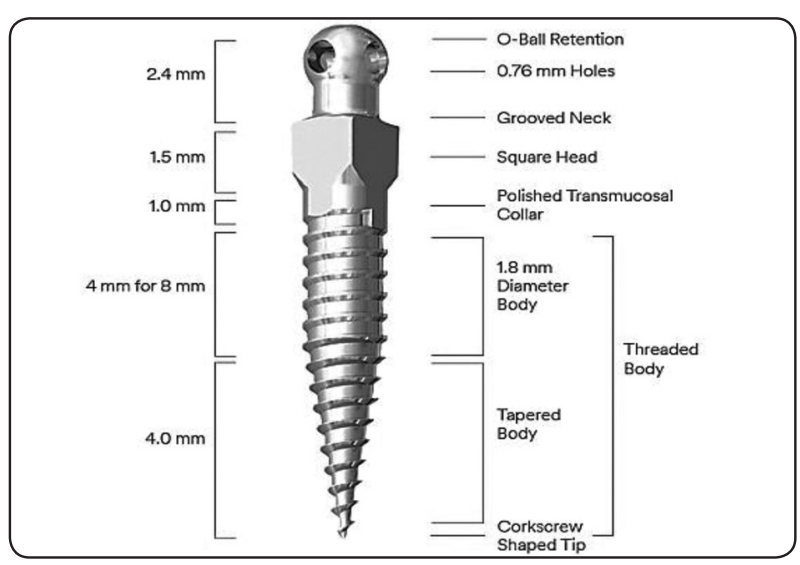

Fig. (1): Prescription of the MI used in this study.

room temperature. Both the cathode and anode were connected to a galvanostatic electrical source $\dagger$ set at 300 Volt for 90 seconds. ${ }^{6-9}$ The MIs were cleaned by copious stream of deionized water for 3 minutes for each, then they were dried in hot dry oven for one hour at $80^{\circ} \mathrm{c}$. The process pf anodization was performed at Faculty of science, Mansoura university. After cooling, each MI was packed separately in tightly-sealed sterilization pouch ready for sterilization. Before insertion, MIs were sterilized by highly disinfection sterilization cycle, packed and stored in tightly closed container ready for insertion.

Banding of upper and lower 1st molars and bonding of whole other teeth mesial to them by using preadjusted edgewise MBT prescription brackets* $(0.022 \times 0.028$ inch bracket slot $)$ were done for each patient.

Since one of our inclusion criteria's was that patients should have no or mild crowding. So, we postponed the extraction of the maxillary 1st bicuspids till after the insertion of MIs and immediately before starting the retraction stage. This allowed utilizing the anchorage value of $1 \mathrm{st}$ bicuspids to shorten the duration of leveling and alignment stage. It also accelerated the en- masse retraction through the freshly obtained socket (regional accelerated phenomena) and reduced the appearance of vertical gingival groove formed between the retracted canines and the maxillary 2 nd premolars ${ }^{10}$.

Leveling and aligning stage was continued by another series of St.St. archwires till reaching to $(0.019 \times 0.025 \mathrm{In})$ St.St. archwire which, was left for 4 weeks to ensure that the wire was passively seated in the whole bracket slots and bands' tube. Insertion of both types of MIs in the right and left sides of the patients were done randomly by opaque sealed envelopes method to prevent bias.

Insertion of MIs were done after finishing the leveling and alignment stage to be sure that roots' parallelism were achieved to gain the sufficient space needed for safe insertion of MIs. The space between maxillary 2nd bicuspids and 1st molars was evaluated by periapical radiograph for the availability of sufficient mesio-distal width for safe insertion of MIs. A metal surgical locator was made of 0.5 $\mathrm{mm}$ round St St wire and used for correct positioning of the MI. Periapical radiograph with parallel cone technique was taken to determine the accurate point for MI insertion.

Locator was then removed; MI was ejected from its sterile packing, and loaded into the straight hand driven MI driver. The MI tip was contacted the buccal alveolar bone at the correct insertion point. MI was self-drilled in the inter radicular area between the roots of upper 2nd bicuspid and 1st molar at the muco-gingival junction $(8-10 \mathrm{~mm}$ from the main arch wire) at an angle $30^{\circ}-40^{\circ}$ from the teeth long axis. The insertion of the minimplants were done by the same orthodontist. MIs were left unloaded for 2 weeks till healing of the soft tissue . Bilateral extraction of maxillary 1st bicuspids were done im-

\footnotetext{
* El Nasr Pharacaceutical Chemical Co, Egypt.

** PASCO Scientific, Model 1030 A High voltage supply. USA
} 
mediately before starting en-masse retraction. The brackets of the four incisor teeth were tied by elastic tie. Canines on both sides were firmly ligated to the main arch wire with soft St St ligature wire $(0.010$ In), to allow controlling the canines and prevent their distal tipping and rotation during retraction. The brackets of both 2 nd bicuspids were passively ligated by $(0.010 \mathrm{in})$ soft St.St. ligature wire to decrease the friction during retraction and allow free sliding of the arch wire ${ }^{11}$. Closed coil spring was extended from the MI head to along hock secured onto the main arch wire between the maxillary lateral incisor and canine on both sides (Figure 2). A constant $200 \mathrm{~g}$ retraction force per side measured by force gauge* was applied., ${ }^{4,12,13}$ The average observation period lasted 9-12 months. The collected data were analyzed statistically with the McNemara test and using Statistica software version 8.0.

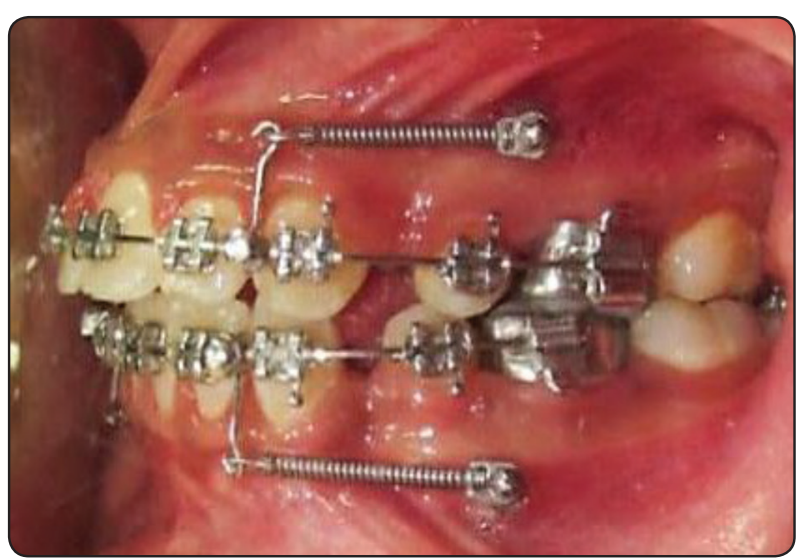

Fig. (2): En mass retraction using the minimplants.

\section{RESULTS}

In total, 40 of 54 minimplants were able to achieve the treatment goals. In group A (anodized), $22(81.5 \%)$ mini-screw implants presented longterm stability, while in group B (control), only
$18(66 \%)$ minimplants were stable throughout the treatment. This difference was statistically significant $(\mathrm{P}=.0311)$. The total success rate for all inserted miniscrew implants was $74 \%$. (Table 1 )

TABLE (1) Minimplant Stability and Failure Distribution

\begin{tabular}{|c|c|c|c|c|}
\hline & \multicolumn{2}{|c|}{ Group A ( anodized) } & \multicolumn{2}{|c|}{ Group B (control) } \\
\hline $\begin{array}{c}\text { Patient } \\
\text { No. }\end{array}$ & $\begin{array}{l}\text { Failure (Weeks } \\
\text { After Insertion) }\end{array}$ & Stable & $\begin{array}{l}\text { Failure (Weeks } \\
\text { After Insertion) }\end{array}$ & Stable \\
\hline 1 & $*(9)$ & & & $*$ \\
\hline 2 & & $*$ & $*(7)$ & \\
\hline 3 & & $*$ & & $*$ \\
\hline 4 & $*(10)$ & & & * \\
\hline 5 & & $*$ & $*(5)$ & \\
\hline 6 & & $*$ & & $*$ \\
\hline 7 & & $*$ & $*(4)$ & \\
\hline 8 & $*(6)$ & 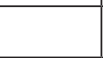 & & $*$ \\
\hline 9 & & $*$ & & $*$ \\
\hline 10 & & $*$ & $*(9)$ & \\
\hline 11 & $*(4)$ & 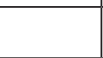 & & $*$ \\
\hline 12 & & $*$ & $*(8)$ & \\
\hline 13 & & $*$ & & $*$ \\
\hline 14 & & $*$ & & $*$ \\
\hline 15 & & $*$ & $*(7)$ & \\
\hline 16 & & $*$ & & $*$ \\
\hline 17 & & $*$ & $*(5)$ & \\
\hline 18 & & $*$ & & $*$ \\
\hline 19 & $*(8)$ & & & $*$ \\
\hline 20 & & $*$ & & $*$ \\
\hline 21 & & $*$ & $*(4)$ & \\
\hline 22 & & $*$ & & $*$ \\
\hline 23 & & $*$ & & $*$ \\
\hline 24 & & * & $*(6)$ & $*$ \\
\hline 25 & & $*$ & & $*$ \\
\hline 26 & & $*$ & & $*$ \\
\hline 27 & & $*$ & & $*$ \\
\hline $\begin{array}{l}\text { Total, } \\
\mathrm{n}(\%)\end{array}$ & $5(18.5)$ & $\begin{array}{c}22 \\
(81.5)\end{array}$ & $9(33)$ & $\begin{array}{c}18 \\
(66)\end{array}$ \\
\hline
\end{tabular}

$$
P=.0311 . \quad *=y e s .
$$

*Morelli Ortodontia, Sorocaba, S.P, Brazil. 


\section{DISCUSSION}

Titanium MIs had enriched the orthodontic anchorage armamentarium; these temporary anchorage devices provide an absolute anchorage. MIs allowed the orthodontic treatment to progress with no anchorage loss and minimal patient's cooperation leading to good treatment outcome in short time..$^{14}$

The ideal orthodontic MIs should provide stationary anchorage with no displacement during the active treatment. ${ }^{15}$ Most of the studies concerned with the stability of orthodontic MIs, reported significant secondary displacement of the MIs under

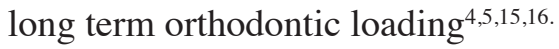

It is quite likely that orthodontic mini-screw implants may not obtain long-term stability because of many factors. These factors may be assigned to different groups: patient related (systemic diseases, smoking, habits, hygiene, the level of immunity, etc), orthodontist related (treatment methodology, experience), and MI related (size, surface coating, and shape). ${ }^{8-14}$

The null hypothesis of this study was rejected. Anodized MI presented long-term stability compared to smooth surface MI. This can be explained by the fact that anodization improved the chemical composition of the surface of MIs where, it produced a thick porous layer of the titanium oxide. Such treatment enhanced the mechanical interlocking at the bone MIs interface. It also improved adhesion, proliferation of osteoblastic cells and promoting osseointegration. ${ }^{17-19}$ The resultant of such treatment was, $3 \mathrm{D}$ bone formation around the MIs and greater bone to implants' contact which enhanced the stability of MIs. ${ }^{19}$

The success rate in this study was $22(81.5 \%)$ anodized mini-screw implants, while only $18(66 \%)$ smooth surface minimplants were stable throughout the treatment. The literatures reported different success rates, Tseng et $\mathrm{al}^{20}$ reported success rate of $91 \%$ after examining the stability of 45 MIs used in orthodontic treatment. On the other hand, Cheng et al, ${ }^{21}$
Costa et $\mathrm{al}^{22}$ and Miyawaki et $\mathrm{a}^{13}$ reported success rates of $89 \%, 87.5 \%$ and $84 \%$ respectively. This controversy may be attributed to the different study designs and durations.

Studying the displacement behavior of both types of MIs was done under one of their most common indications, i.e. en-masse retraction of the anterior teeth. This helped to subject the MIs to a real test. En masse retraction allowed subjecting these MIs to the highest orthodontic force for relatively long loading duration. This study design was similar to that used by many authors ${ }^{1,4,17-21}$ while, others tested the stability of MIs during canines retraction where, they were unable to subject the MIs to high orthodontic forces for long duration. ${ }^{13,20}$

MIs design, length and diameter had been proved to affect the stability and success rate of MIs. ${ }^{17,18}$ This study utilized only one type of MIs having the same design, size and of suitable length and diameter (1.8 $\mathrm{mm}$ diameter and $8 \mathrm{~mm}$ length) which allowed them to withstand the heavy applied force for long duration. Some authors assessed the displacement behavior of MIs utilizing MIs not having the same length or having reduced diameter which might affect their results..$^{20,15,18}$

Both types of MIs were randomly self drilled in the inter-radicular area between the roots of the maxillary 2nd bicuspid and 1st molar at an angle $30^{\circ}-40^{\circ}$ to the long axis of the teeth on both sides of each patient (split mouth design). This is a commonly preferred position for MIs insertion because of its accessibility for various orthodontic mechanics. ${ }^{18}$ It also has a large available space and increased cortical bone thickness that ensured safe and stable insertion of MIs. ${ }^{19-22}$ Such insertion angulation of MIs allowed engaging more cortical bone thickness and ensured safe insertion away from the adjacent roots.$^{19,20,21}$

Although the results of this study are promising, further investigations are needed to evaluate long term stability of surface treated minimplants. 


\section{CONCLUSION}

Anodized surface treated orthodontic miniscrew implants are more stable than smooth surface one during en-mass retraction.

\section{REFERENCES}

1. Liu H, Lv T, Wang NN, Zhao F, Wang KT and Liu DX. Drift characteristics of miniscrews and molars for anchorage under orthodontic force: 3-dimensional computed tomography registration evaluation. Am. J. Orthod. Dentofac. Orthop. 2011;139(1):e83-9.

2. Bondemark L and Kurol J. Distalization of the first and second molars simultaneously with repelling magnets. Eur J Orthod. 1992;14(4):264-72.

3. McGuire MK, Scheyer ET and Gallerano RL. Temporary anchorage devices for tooth movement: a review and case reports. J. Periodontol. 2006;77(10):1613-24.

4. Liou EJ, Pai BC and Lin JC. Do miniscrews remain stationary under orthodontic forces? Am. J. Orthod. Dentofac. Orthop. 2004;126(1):42-7.

5. Nienkemper M, Handschel J and Drescher D. Systematic review of mini-implant displacement under orthodontic loading. Int. J. Oral Sci. 2014;6(1):1-6.

6. Cho IS, Kim SK, Chang YI and Baek SH. Cell adhesion and in vivo osseointegration of sandblasted/ acid etched/anodized dental implants. Int. J. Mol. Sci. 2015;16(5):10324-36.

7. Cho IS, Kim SK, Chang YI and Baek SH. In vitro and in vivo mechanical stability of orthodontic mini-implants: Effect of sandblasted, large-grit, andanodic-oxidation vs sandblasted, large-grit, and acid-etching. Angle Orthod. 2012;82(4):611-7.

8. Uttiya S, Contarino D, Prandi S, Carnasciali MM, Gemme G, Mattera L and Cavalleri O. Anodic Oxidation of Titanium in Sulphuric Acid and Phosphoric Acid Electrolytes. J. Mater. Sci. Nanotechnol. 2014;1(1):1-8.

9. Park TY, Eom SH, Kim MD, Kim SH, il Kim H, Jeon GR and Shin JW . Effects of Surface Morphology of Titanium Anodic-oxidized with Sulphuric Acid and Phosphoric Acid on Osteogenesis. Clin. Exp. 2005;7:506-17.

10. Yu JY, Lee W, Park JH, Bayome M, Kim Y and Kook YA Histologic effects of intentional-socket-assisted orthodontic movement in rabbits. Korean J Orthod. 2012;42(4): 207-17.
11. Kojima Y, Kawamura J and Fukui H. Finite element analysis of the effect of force directions on tooth movement in extraction space closure with miniscrew sliding mechanics. Am J Orthod Dentofac. Orthop 2012;142(4):501-8.

12. Lee SY, Cha JY, Yoon TM and Park YC. The effect of loading time on the 1 stability of mini-implant. Korean J Orthod. 2008;38(3):149-58.

13. Miyawaki S, Koyama I, Inoue M, Mishima K, Sugahara $\mathrm{T}$ and Takano- Yamamoto T. Factors associated with the stability of titanium screws placed in the posterior region for orthodontic anchorage. Am J Orthod Dentofac. Orthop 2003;124(4):373-8

14. El-Beialy AR, Abou-El-Ezz AM, Attia KH, El-Bialy AM and Mostafa YA. Loss of anchorage of miniscrews: A 3-dimensional assessment. Am. J. Orthod. Dentofac. Orthop. 2009;136(5):700-7.

15. Kim SH, Cho JH, Chung KR, Kook, Yoon Ah and Nelson G. Removal torque values of surface-treated miniimplants after loading. Am. J. Orthod. Dentofac. Orthop. 2008;134(1):36-43

16. Alves M, Baratieri C and Nojima LI. Assessment of miniimplant displacement using cone beam computed tomography. Clin. Oral Implants Res. 2011;22(10):1151-6.

17. Deligianni DD, Katsala N, Ladas S, Sotiropoulou D, Amedee $\mathrm{J}$ and Missirlis YF. Effect of surface roughness of the Ti alloy Ti-6Al-4V on human bone marrow cell response and on protein adsorption. Biomaterials 2001;22(11):1241-51.

18. Albrektsson T and Wennerberg A. Oral implant surfaces: Part 1-Review focusing on topographic and chemical properties of different surfaces and in vivo responses to them. Int. J. Prosthodont. 2004;17(5):536-43.

19. Karmarker S, Yu W and Kyung HM. Effect of surface anodization on stability of orthodontic microimplant. Korean J. Orthod. 2012;42(1):4-10.

20. Tseng YC, Hsieh $\mathrm{CH}$, Chen $\mathrm{CH}$, Shen YS, Huang IY and Chen CM. The application of mini-implants for orthodontic anchorage. Int J Oral Maxillofac Surg 2006;35(8):704-7.

21. Cheng SJ, Tseng IY, Lee JJ and Kok SH. A prospective study of the risk factors associated with failure of miniimplants used for orthodontic anchorage. Int J Oral Maxillofac Implant. 2004;19(1).

22. Costa A, Raffainl M and Melsen B. Miniscrews as orthodontic anchorage: a preliminary report. Int J Adult Orthod Orthognath Surg. 1998;13(3):201-9. 